\title{
Healing and recurrence of duodenal ulcer after treatment with tripotassium dicitrato bismuthate (TDB) tablets or cimetidine
}

\author{
I HAMILTON, H J O'CONNOR, N C WOOD, I BRADBURY, AND A T R AXON \\ From the Gastroenterology Unit, General Infirmary, Leeds, and Cardiovascular Epidemiology Unit, \\ University of Dundee, Dundee, Scotland
}

SUMMARY Eighty patients with duodenal ulcer were randomly allocated to treatment with tripotassium dicitrato bismuthate (TDB) tablets or cimetidine. Ulcers healed in $78 \%$ of patients treated with TDB and in $74 \%$ treated with cimetidine, supporting previous observations that the efficacy of these two agents is similar. Duodenal ulcer recurred in $43 \%$ of patients in the 12 months after treatment with $\mathrm{TDB}$ and in $78 \%$ of patients treated with cimetidine, with a significantly greater incidence of recurrence 6-12 months after cimetidine treatment. Tripotassium dicitrato bismuthate tablets may be preferable to cimetidine in the initial management of duodenal ulcer, because they offer a smaller likelihood of recurrence in the 12 months after successful treatment.

Tripotassium dicitrato bismuthate (TDB) is established as an effective agent in the management of duodenal ulcers and several studies comparing TDB with $\mathrm{H}_{2}$-histamine receptor antagonists have demonstrated that these two treatments are capable of healing similar proportions of duodenal ulcers. ${ }^{1-5}$ Some such studies have also shown a decrease in the frequency or rapidity of recurrence of duodenal ulcer after treatment with TDB, when compared with cimetidine ${ }^{1}$ or ranitidine, ${ }^{2}$ but the significance of this observation has been controversial, particularly as other authors have failed to confirm that the initial treatment for duodenal ulcer influences the rate of recurrence. ${ }^{5}$ We have previously reported a randomised study comparing TDB tablets with cimetidine in the treatment of duodenal ulcer ${ }^{3}$ and have now extended that study to include sufficiently large numbers of patients to permit evaluation both of the efficacy of TDB and cimetidine in treatment and of the recurrence of duodenal ulcer in the 12 months after successful treatment with these two agents.

\section{Methods}

PATIENTS

Eighty patients with endoscopically diagnosed duoAddress for correspondence: Dr I Hamilton, University Department of Medicine, Ninewells Hospital and Medical School, Dundee DD1 9SY. Received for publication 19 April 1985
12 months after the end of therapy, or at the earlier development of symptoms, regardless of severity. Some patients in each group attended early for their final clinical and endoscopic review because of denal ulcer were allocated by prior stratified randomisation to receive treatment with either TDB tablets ( 1 tablet tds half an hour before meals and 1 at night two hours after eating), or cimetidine (200 $\mathrm{mg}$ tds and $400 \mathrm{mg}$ nocte) for six weeks. Treatment started within one week of endoscopic diagnosis. All patients who had been taking TDB, $\mathrm{H}_{2}$-histamine receptor antagonists, or carbenoxolone in the three months before diagnosis, or in whom previous treatment with TDB or cimetidine had been unsuccessful, were excluded from the study, as were patients who previously had gastroduodenal surgery. All subjects recorded symptoms and antacid consumption daily on diary cards. Endoscopy was repeated during the final week of treatment to determine ulcer healing, which required complete duodenal re-epithelialisation. Those patients with superficial duodenal ulceration or erosions persisting after treatment were classed as treatment failures. Patients whose ulcers healed during treatment were not offered maintenance therapy, but were asked to return for clinical review three, six, and 12 months after completion of treatment, or at any intermediate stage if they developed recurrent symptoms. Endoscopy was repeated in all patients 
recurrent symptoms, whilst others attended late. The timing of the final review was similar in each group, with a median of 12 (range nine-16) months in both groups.

A double blind double dummy technique was not used, but the study remained blind, vigorous precautions being taken to ensure that all participating clinicians were not aware of the treatment taken by any patient.

Consecutive patients were allocated a number and were issued with the corresponding numbered sealed treatment pack by the hospital pharmacy. Allocation of numbers to treatment groups was by prior randomisation stratified in blocks of 10 to ensure approximately equal distribution of treatments. The study was conducted in two consecutive groups each of 40 patients, and the code detailing the treatment contained in each numbered pack was not broken by any patient until the completion of the entire study for that group of 40 patients. This device allowed interim analysis of the study after completion of the first 40 patients without influencing the results obtained from the remaining patients since each group was entirely independent.

All clinical and endoscopic evaluations were done independently by clinicians who were not aware of the treatment group to which patients were allocated. Thus this was a single blind controlled study.

Groups were compared statistically using $\chi^{2}$ or Student's $t$ test as appropriate, and ulcer recurrence curves compared using the Mantel-Haenszel log rank test.

\section{Results}

Forty one patients were allocated to treatment with TDB and 39 to cimetidine. Groups were comparable with respect to age, sex, duration of history, and previous treatment with either TDB or cimetidine (Table 1). Ulcers healed in $33(81 \%)$ treated with TDB and $29(74 \%)$ treated with cimetidine (NS). Symptomatic relief was also similar in the two groups. Unwanted effects occurred in seven patients taking TDB (headache (two), sore throat (two), diarrhoea, anorexia, and dizziness), and in eight taking cimetidine (tiredness (two), diarrhoea, constipation, headache, weight loss, nausea, dry mouth). Reversible staining of the mouth occurred in 24 of those taking TDB and was confined to this group. No patient was withdrawn from the study because of unwanted effects, but one patient treated with cimetidine needed surgical treatment for haemorrhage from persisting ulceration during the final week of treatment and is classified as a failure of treatment.

Smoking habit did not influence healing of
Table 1 Details of patients allocated to treatment with $T D B$ or cimetidine and response

\begin{tabular}{|c|c|c|}
\hline & $T D B$ & Cimetidine \\
\hline Number & 41 & 39 \\
\hline Mean age (range) & $45(22-72)$ & $46(24-65)$ \\
\hline Sex M:F & $28: 13$ & $30: 9$ \\
\hline Mean length of history (years) & $7 \cdot 6($ SD $7 \cdot 4)$ & $6 \cdot 8($ SD 7-9) \\
\hline $\begin{array}{l}\text { Median duration of present } \\
\text { relapse (range - months) }\end{array}$ & $5(0 \cdot 5-24)$ & $5(1-24)$ \\
\hline \multicolumn{3}{|l|}{ Previous treatment with } \\
\hline TDB & 2 & 1 \\
\hline Cimetidine & 4 & 3 \\
\hline Smokers & 26 & 26 \\
\hline Ulcers healed & $33(78 \%)$ & $29(74 \%)$ \\
\hline \multicolumn{3}{|l|}{ Symptom relief } \\
\hline complete & 30 & 24 \\
\hline moderate & 7 & 8 \\
\hline none & 4 & 7 \\
\hline $\begin{array}{l}\text { Mean duration of treatment } \\
\text { prior to symptom relief } \\
\text { (range) }\end{array}$ & $22(1-42)$ days & $17(1-42)$ days \\
\hline
\end{tabular}

duodenal ulcer in either group, ulcers healing in 21 $(81 \%)$ of 26 smokers and $12(80 \%)$ of 15 nonsmokers treated with TDB and in $17(68 \%)$ of 25 smokers and $12(86 \%)$ of 14 non-smokers treated with cimetidine (NS).

Thirty of 33 patients whose ulcers had healed during treatment with TDB attended for review at three months, and 24 completed the study to an end point of either confirmed ulcer recurrence or confirmed remission at final review, two patients withdrawing six months after completion of treatment and a further four failing to attend for final review. Ulcers had recurred in three patients $(10 \%)$ at three months, in six of the remaining $25(24 \%)$ at six months, and in a further four of 15 attending for final review. Thus the cumulative ulcer recurrence rate was $10 \%$ at three months, $30 \%$ at six months and $43 \%$ at 12 months. Eleven patients were in endoscopically confirmed remission at final review (Table 2).

Of the 29 successfully treated with cimetidine, 23 attended for review at three months and 18 completed the study, four withdrawing at six months and one at final review. Four (17\%) suffered recurrence of ulceration by three months and six of the remaining $15(40 \%)$ at six months. Recurrence of ulcer at these times does not differ significantly from patients treated with TDB. At final review ulcers had recurred in all the remaining eight patients and none were in remission. At 12 months the cumulative recurrence rate of $78 \%$ in cimetidine treated patients is significantly greater than the $43 \%$ recurrence rate in those treated with TDB $(p<0.01)$. This analysis assumes that patients withdrawing from the 
Table 2 Details of recurrence of ulceration in each treatment group during 12 months after completion of treatment

\begin{tabular}{|c|c|c|c|c|c|c|c|c|}
\hline \multirow{2}{*}{$\begin{array}{l}\text { Time since } \\
\text { completion of } \\
\text { treatment (months) }\end{array}$} & \multicolumn{4}{|l|}{$T D B$ patients } & \multicolumn{4}{|c|}{ Cimetidine patients } \\
\hline & $\begin{array}{l}\text { Remaining } \\
\text { in study }\end{array}$ & Defaulted & $\begin{array}{l}\text { Attended } \\
\text { (recurrence) }\end{array}$ & $\begin{array}{l}\text { Cumulative } \\
\text { recurrence (\%) }\end{array}$ & $\begin{array}{l}\text { Remaining } \\
\text { in study }\end{array}$ & Defaulted & $\begin{array}{l}\text { Attended } \\
\text { (recurrence) }\end{array}$ & $\begin{array}{l}\text { Cumulative } \\
\text { recurrence (\%) }\end{array}$ \\
\hline 0 & $33 / 41$ healed & - & - & - & 29/31 healed & - & - & - \\
\hline 3 & 33 & 3 & $30(3)$ & $3(10)$ & 29 & 6 & $23(4)$ & $4(14)$ \\
\hline 6 & 27 & 2 & $25(6)$ & $9(30)$ & 19 & 4 & $15(6)$ & $10(43)$ \\
\hline 12 & 19 & 4 & $15(4)$ & $13(43)$ & 9 & 1 & $8(8)$ & $18(78)$ \\
\hline
\end{tabular}

study were free of recurrence, which may be inappropriate and alternative techniques have therefore been used to overcome errors in interpretation of the results arising from withdrawal of some patients.

Excluding all patients who withdrew from the study during follow up, ulcers recurred in 13 of 24 TDB treated patients and 11 remained in remission for 12 months, whilst all of the 18 patients treated with cimetidine completing the study suffered recurrent ulcers $(\mathrm{p}<0.001)$.

In view of the variable number of patients in each group withdrawing from the study the recurrence of duodenal ulcer, in each treatment group over the period of follow up has been compared using life table techniques. The probability of being in remission has been plotted against time after completion of treatment, both assuming that withdrawal from the study is unrelated to recurrence of ulceration (Fig. 1) and assuming that withdrawal is indicative of relapse (Fig. 2). Analysis of these curves by 2-tailed $\log$ rank test shows a statistically significant difference in favour of TDB in each case $(p<0.02$ for Figure 1, $<<0.01$ for Figure 2). Calculation of confidence intervals from the data presented in Figure 1 (assuming withdrawal is independent of relapse) shows the observed frequency of recurrent ulceration at 12 months to be compatible with a reduced incidence of recurrence of between $17 \%$ and $61 \%$ in patients treated with TDB when compared with those treated with cimetidine, while if withdrawal is indicative of recurrence (Fig. 2) the reduction in recurrence after TDB treatment lies between $10 \%$ and $48 \%$.

The majority of recurrences of ulceration were symptomatic, with only two asymptomatic recurrences in each group. Age, sex, duration of ulcer history and smoking habit were similar in patients in whom ulcers recurred to those continuing in remission.

\section{Discussion}

Tripotassium dicitrato bismuthate tablets appear to be as effective as cimetidine in healing duodenal ulcers during six weeks' treatment, confirming our preliminary observations in the first 40 of these patients ${ }^{3}$ and supporting previous suggestions that the efficacy of TDB is comparable with that of $\mathrm{H}_{2}$-histamine receptor antagonists. ${ }^{1-5}$ Confidence intervals calculated from the results observed in this study show these results to be consistent with a $15 \%$ advantage for cimetidine in healing duodenal ulcer, or with a $23 \%$ advantage for TDB.

As TDB and cimetidine are able to heal similar proportions of duodenal ulcer with few unwanted effects, the ability to induce a more prolonged remission might prove to be a considerable advantage in the treatment of duodenal ulcer. We have

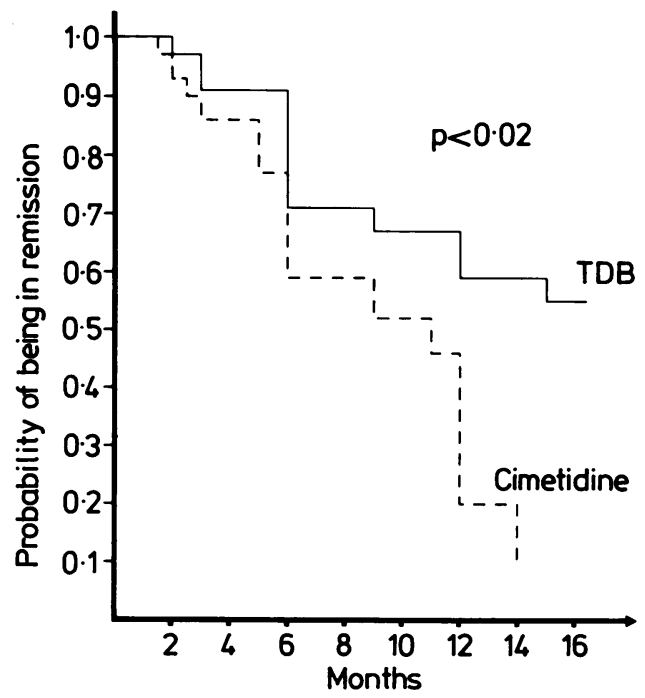

Fig. 1 Probability of being in remission of duodenal ulcer against duration of period of follow up after treatment with tripotassium dicitrato bismuthate or cimetidine assuming withdrawal from the follow up by the patient is independent of recurrent ulceration. 


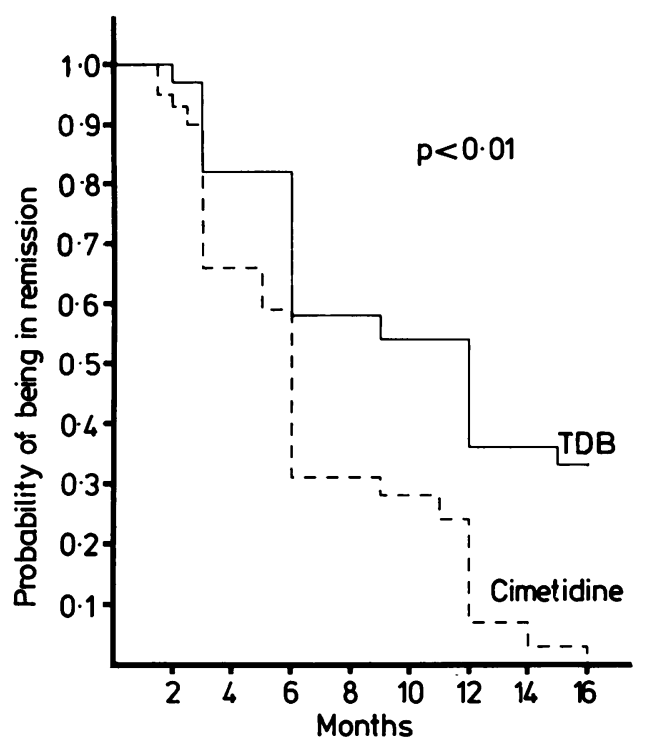

Fig. 2 Probability of being in remission against duration of follow up assuming withdrawal is indicative of recurrent ulceration.

found ulcer recurrence to be less frequent after treatment with TDB than with cimetidine, decreased recurrence occurring in the latter half of the 12 months for which these patients were observed. Bianchi-Porro and coworkers have reported preliminary results of a multicentre comparative studyof TDB and ranitidine, in which recurrence was significantly lower in the first six months after treatment with $\mathrm{TDB},{ }^{2}$ and suggest that their finding is the result of a more normal re-epithelialisation after TDB. ${ }^{6} \mathrm{~A}$ bactericidal effect of TDB on gastric campylobacter like organisms has also been proposed as an explanation for prolonged remission of ulcers after treatment with TDB,${ }^{7}$ but it is difficult to accept that such mechanisms will only induce a decline in relapse rate six to 12 months after completion of treatment, and not in the initial six months. Treatment with other agents capable of healing duodenal ulcer such as sucralfate ${ }^{8}$ and antacid/anticholinergic combinations ${ }^{9}$ may also lead to less frequent, or less rapid recurrences of ulceration than treatment with $\mathrm{H}_{2}$-histamine receptor antagonists. It has been suggested that $\mathrm{H}_{2}$ histamine receptor antagonists will induce a more rapid recurrence of ulcer on stopping treatment, ${ }^{10}$ but ulcer recurrence is not more frequent after treatment with cimetidine than with placebo, ${ }^{911}$ despite the possibility that ulcers healing on placebo may represent a different population than those healing on cimetidine. ${ }^{11}$

Bianchi-Porro has recently observed a recurrence rate of duodenal ulcer treated with TDB and subsequently given no maintenance treatment to be similar to that occurring whilst patients treated with $\mathrm{H}_{2}$-histamine receptor antagonists were continuing to take maintenance treatment with cimetidine. ${ }^{12}$

Whilst the time at which a smaller ulcer relapse rate occurred differs in this study from the multicentre comparison, ${ }^{2}$ both studies confirm the initial observation that recurrence was less frequent in the 18 months after treatment with TDB than with cimetidine,${ }^{1}$ although this observation was based on incomplete endoscopic observation, and its clinical significance has been uncertain, particularly as Kam and Piper failed to confirm a difference in recurrence rates in a similar study, ${ }^{5}$ perhaps reflecting differences in ulcer disease between populations. Calculation of the confidence limits for a difference in ulcer recurrence from the results of that study, ${ }^{5}$ however, shows the observed frequency of recurrent ulceration to be compatible with a $3 \%$ reduction in recurrence in patients treated with cimetidine, or with a $28 \%$ reduction in recurrence in those treated with TDB, whilst similar calculation from the results reported by Martin et al ${ }^{1}$ suggest the advantage in favour of TDB to lie between $22 \%$ and $68 \%$. The smaller number of patients studied by Van Trappen ${ }^{4}$ yield confidence limits between $3 \%$ advantage for cimetidine and $50 \%$ advantagefor TDB. The results of each of these comparative studies are therefore compatible with TDB offering a $20 \%$ reduction in duodenal ulcer recurrence in the 12 months after successful healing and our results support this possibility.

Although the number of patients remaining in each treatment group six months after completing treatment was small due to earlier ulcer recurrence and withdrawal by the patient, the statistical techniques used take account of the changing size of the population, and the numbers are sufficient to demonstrate statistical significance between groups. The treatment groups were similar with respect to length of history and duration of recent symptoms, smoking habit and age, and these factors cannot explain the observed decrease in relapse rates. The design of this study may be criticised because a double blind double-dummy technique was not used. Such a design would have involved each patient in taking nine tablets daily and we believe this would be likely to reduce compliance, particularly in a study requiring large numbers of patients and prolonged follow up. The design used enabled the interim assessment of results when half the patients had completed the study without affecting the validity of the results obtained in the remaining 
patients, and ensured that all clinicians involved in entry and assessment of patients were not aware of the treatment group to which patients were assigned. Thus, this design was adopted to reduce the possibility of bias and the possibility of error due to poor compliance. Despite this precaution a considerable number of patients withdrew from the study during the 12 months after completion of treatment. Withdrawal may have been due to continuing freedom from symptoms, or to relapse with recurrent symptoms prompting a desire to seek alternative advice. We have therefore analysed our results assuming each of these explanations to be correct. We believe that duodenal ulcer recurrence may depend in part on the treatment used to induce initial healing, and that in this respect at least TDB tablets may have an advantage over cimetidine in the treatment of duodenal ulcer, because they are as likely to induce healing, yet offer a possibility of the patient remaining in remission over the next 12 months, a possibility which cimetidine was not able to offer in this study.

\section{References}

1 Martin DF, Hollanders D, May SJ, Ravenscroft MM, Tweedle DEF, Miller JP. Difference in relapse rates of duodenal ulcer after healing with cimetidine or tripotassium dicitrato bismuthate. Lancet 1981; 1: 7-10.

2 Bianchi-Porro G, Barbara L, Cheli R, Dalmonte PR, Mazzacca G. Comparison of tripotassium dicitrato bismuthate tablets and ranitidine in healing and relapse of duodenal ulcers. [Abstract]. Gut 1984; 25: A565.
3 Hamilton I, Worsley BW, O'Connor HJ, Axon ATR. The effects of tripotassium dicitrato bismuthate tablets or cimetidine in the treatment of duodenal ulcer. Gut 1983; 24: 1148-51.

4 Van Trappen G, Rutgeerly P, Broekart L, Jansens J. Randomised open controlled trial of colloidal bismuthate subsitrate tablets and cimetidine in the treatment of duodenal ulcer. Gut 1980; 21: 329-33.

5 Kam JY, Piper DW. Cimetidine and colloidal bismuth in treatment of chronic duodenal ulcer. Digestion 1982; 23: 73-9.

6 Moshal MG, Gregory MA, Pillay C, Spitaels JM. Does the duodenal cell ever return to normal? A comparison between treatment with cimetidine and De Nol. Scand J Gastroenterol 1973; 14: suppl. 54: 48-51.

7 Marshall BJ, Warren JR. Unidentified curved bacilli in the stomach of patients with gastritis and peptic ulceration. Lancet 1984; 1: 1311-4.

8 Marks IN, Wright JP, Lucke W, Girdwood AH. Relapse rates following initial ulcer healing with sucralfate and cimetidine. Scand J Gastroenterol 1983; 18: suppl. 83: 53 .

9 Strom M, Gotthard R, Bodemar G, Walun A. Antacid/ anticholinergic, cimetidine and placebo in treatment of active peptic ulcers. Scand J Gastroenterol 1981; 16: 593-602.

10 McLean AJ, Harrison PM, Ionnides-Damos LL, Byrne AJ, McCarthy P, Dudley FJ. Microbes, peptic ulcer and relapse rates with different drugs. Lancet 1984; 2: 525-6.

11 Burland WL, Hawkins ISW, Beresford J. Cimetidine treatment for the prevention of recurrence of duodenal ulcer: an international collaborative study. Postgrad Med J 1980; 56: 173-6.

12 Bianchi-Porro G, Lazzaroni M, Petrillo M, DeNicola C. Relapse rates in duodenal ulcer patients formerly treated with bismuth subsitrate or maintained with cimetidine. Lancet 1984; 2: 698. 
a rapidly developing field. Virtually all of the ultrasound images are shown with the corresponding radiology and colour photographs of the lesion obtained at endoscopy. There are also many examples of the corresponding histological specimens and for radiologists and gastroenterologists embarking on the practice of endoscopic ultrasound this book will be of great value because the authors experiences are reflected in the very wide range of lesions shown. Conventional endoscopists will also have the added bonus of seeing what lies beneath the surface picture and perhaps think more in terms of the three dimensional anatomy.

My major criticism of the book would be that having seen many of the originals, the ultrasound images have reproduced poorly as have the radiographs. I am generally rather opposed to the atlas format which tends to be short on explanation and basic data but an atlas can be very useful in the early stages of a technique to assist the neophyte. This book will be very valuable reading for anybody actively doing endosonography of the upper or lower GI tract and will certainly be useful reading to all those considering entering what will be the major growth area in diagnostic ultrasonography in the next five years.

W R LEES

\section{News}

\section{European Association for the Study of the Liver}

The 22nd meeting of this association will take place in Turin on 3-5 September, 1987. Information may be obtained from Professor G Verne, Department of Gastroenterology, San Giovanni Battista Hospital, Turin, Italy.

5th International Symposium on Endoscopic Ultrasonography

This will take place in Munich, Germany on 10 and 11 July, 1987. Further details may be obtained from $T$ Rösch, II Medizinische Klinik und Poliklinik der Techn. Universitat München, Klinikum rechts der Isar, Ismaninger Str. 22, 8000 München 80, FRG.

First Wexner Symposium on Developmental Gastroenterology

This symposium will be held in Columbus, Ohio,
USA from 13-15 September, 1987. Further information may be obtained from Professor H R Sloan, Children's Hospital, 700 Columbus Drive, Columbus, Ohio 43205, USA.

XXVI World Congress of the International College of Surgeons

The First World Postgraduate Course in Surgery will be held in Milan, Italy from 3-9 July 1988. Details from Clinica Chirgurgica III, Università degli Studi, Via F Sforza 35, 20122, Milan, Italy.

\section{Correction}

We apologise for an error made by a previous printer in the article on p 106 of Gut 1986; 27 by Hamilton $e t$ $a l$, where four lines from the bottom of column 2 have been transposed to the top. A correct version is printed below:

... denal ulcer were allocated by prior stratified randomisation to receive treatment with either TDB tablets ( 1 tablet tds half an hour before meals and 1 at night two hours after eating), or cimetidine (200 $\mathrm{mg}$ tds and $400 \mathrm{mg}$ nocte) for six weeks. Treatment started within one week of endoscopic diagnosis. All patients who had been taking TDB, $\mathrm{H}_{2}$-histamine receptor antagonists, or carbenoxolone in the three months before diagnosis, or in whom previous treatment with TDB or cimetidine had been unsuccessful, were excluded from the study, as were patients who previously had gastroduodenal surgery. All subjects recorded symptoms and antacid consumption daily on diary cards. Endoscopy was repeated during the final week of treatment to determine ulcer healing, which required complete duodenal re-epithelialisation. Those patients with superficial duodenal ulceration or erosions persisting after treatment were classed as treatment failures. Patients whose ulcers healed during treatment were not offered maintenance therapy, but were asked to return for clinical review three, six, and 12 months after completion of treatment, or at any intermediate stage if they developed recurrent symptoms. Endoscopy was repeated in all patients 12 months after the end of therapy, or at the earlier development of symptoms, regardless of severity. Some patients in each group attended early for their final clinical and endoscopic review because of ... 